\title{
NOVOS MEIOS DE MEMÓRIA: LIVROS E LEITURA NA ÉPOCA DOS WEBLOGS
}

NEW MEMORY MEDIA: BOOKS AND READING IN THE AGE OF WEBLOGS

Vera Dodebei

Doutora em Comunicação e Cultura (ECO/UFRJ)

Professora Associada I no PPGMS/UNIRIO

Líder do Grupo de Pesquisa CNPq "Memória Social, Tecnologia e Informação"

Pesquisadora em Produtividade e Pesquisa do CNPq

dodebei@terra.om.br

\section{Resumo}

A memória é construída a partir do presente por uma tensão entre duas ações: lembrar e esquecer, e está sempre dialogando com os objetos que recortamos para analisar a condição do conhecimento na contemporaneidade. O texto deste artigo está organizado em três partes. $\mathrm{Na}$ primeira parte, enfrentamos o objeto "livro", seu surgimento na sociedade, sua importância para a transmissão dos saberes, o poder de controle de atitudes, como os homensmemórias criados por Bradbury em Fahrenheit 451 e seu possível ocaso face às tecnologias de suporte da informação. A segunda parte desatrela a ação de ler de seu suporte mais tradicional e trata a "leitura" como objeto independente, sugerindo-se, a partir das reflexões de Regina Zilberman, Alberto Manguel e Paulo Freire que somos constituídos para ler o mundo, não importam os mecanismos que nos valemos para alcançar esse objetivo. Na terceira e última parte, apresentamos alguns indicadores de modos possíveis de existência de meios de memória no ambiente virtual, com comentários sobre o papel dos blogs e websites em relação à escrita firmada em papel.

Palavras-chave: Memória virtual. Livro. Leitura. Blogs. Patrimônio digital.

O bicho alfabeto

O bicho alfabeto tem vinte e três patas

ou quase

por onde ele passa nascem palavras

e frases

como frases se fazem asas palavras

$o$ vento leve

o bicho alfabeto passa

fica o que não se escreve

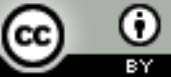
Esta obra está licenciada sob uma Licença Creative Commons.

DOI 2924.2009v14nesp1p129

Paulo Leminski

Enc. Bibli: R. Eletr. Bibliotecon. Ci. Inf., ISSN 1518-2924, Florianópolis n. esp., 1. sem. 2009. 


\section{A CONSTRUÇÃO DA MEMÓRIA: O LIVRO, A LEITURA, A ESCRITA DIGITAL}

O poema de Leminski nos convida a pensar a relação entre meios de memória, particularmente o que diz respeito à informação escrita, e a condição de permanência daquilo que se acumula ao longo do tempo, como a História nos sinaliza. Ao contrário do ditado popular "vale o escrito", o bicho alfabeto passa, fica o que não se escreve. O medo da perda de informações visuais com as quais nos habituamos a conviver, sejam livros, fotografias, manuscritos, nos colocou a partir da década de 90 do século XX no mundo "memorioso", em que a obsessão pela memória, como afirma Andréas Huyssen (2000), poderá levar a uma possível paralisação do processo de criação. O convite a voltar ao passado poderia ir mais longe à linha do tempo e nos conduzir à época anterior ao surgimento da era da tecnologia da escrita, quando a transmissão dos saberes era feita de forma oral, sem a preocupação com registros em suportes materiais, a não ser nossa memória individual. Esses dois meios de memória (a oralidade e a escrita) coexistem nos dias atuais e entram em disputa com uma nova mídia virtual do mundo digitalizado. À memória individual que ao invés de acumular processa para produzir novas informações, e à memória auxiliar criada pela sociedade da escrita representada por arquivos, bibliotecas e museus, juntam-se a memória informática que transforma o visual e o oral em números.

O livro nos parece, neste cenário de conflitos que envolvem a produção de subjetividades e a constituição de memórias, o objeto adequado para investigar como a sociedade pensa o processo de transmissão de conhecimentos para o futuro. Os meios de memória do futuro serão cumulativos ou seletivos? Ao reunir autores que pudessem contribuir para um artigo sobre a aventura do livro como pensou Chartier (1998), desde sua criação até sua transformação como parece ocorrer nestes dias de virtualidade e digitalização, organizamos uma pequena biblioteca circunstancial para esse fim, e nela incluímos além dos autores já citados, Regina Zilberman com a obra Fim do livro, fim dos leitores? (ZILBERMAN, 2001); o número 142 da revista Tempo Brasileiro, intitulada O lugar do livro hoje (O lugar, 2000) que representa a coletânea de textos apresentados no colóquio internacional O lugar do livro: entre a nação e o mundo, realizado na Academia Brasileira de Letras entre 28 e 31 de agosto de 2000; a obra ficcional de Ray Bradbury (2003) - Fahrenheit 451, filmada em 1966 por François Truffaut; a obra clássica de Wilson Martins, A palavra escrita (MARTINS, 1957) e a obra de Alberto Manguel neste momento representada por três ensaios: A biblioteca à noite Enc. Bibli: R. Eletr. Bibliotecon. Ci. Inf., ISSN 1518-2924, Florianópolis n. esp., 1. sem. 2009. 
(MANGUEL, 2006), No bosque do espelho: ensaios sobre as palavras e o mundo (MANGUEL, 2000), e Uma história da leitura (MANGUEL, 1997).

A conversa que se seguirá possivelmente não esgotará esse tema complexo sobre a memória do mundo e muitos autores certamente poderão ser adicionados pelos próprios leitores, que assim, darão continuidade à discussão. A memória se constitui, quer seja ela individual ou coletiva, a partir do presente, por uma tensão entre duas ações: lembrar e esquecer, e estará sempre dialogando com os objetos que recortamos para analisar a condição do conhecimento na contemporaneidade. $\mathrm{O}$ texto deste artigo está organizado em três partes. Na primeira parte, enfrentaremos o objeto "livro", seu surgimento na sociedade, sua importância para a transmissão dos saberes, o poder de controle de atitudes, como os homens-memórias criados por Bradbury em Fahrenheit 451 e seu possível ocaso face às tecnologias de suporte da informação. A segunda parte desatrelará a ação de ler de seu suporte mais tradicional e tratará a "leitura" como objeto independente, sugerindo-se, a partir das reflexões de Regina Zilberman, Alberto Manguel, Paulo Freire que somos constituídos para ler o mundo, não importa os mecanismos que nos valemos para alcançar esse objetivo. Na terceira e última parte, nos esforçamos para apresentar alguns indicadores de modos possíveis de existência de meios de memória no ambiente virtual, com comentários sobre o papel dos blogs e websites em relação à escrita firmada em papel.

\section{O LIVRO}

"A valorização do leitor e da leitura parece chegar tarde demais: anuncia-se o final da era do livro, sua substituição por multimídias interativas, a metamorfose do consumidor de obras escritas no nerd internauta, aventureiro que percorre até agora desconhecidos universos virtuais" (ZILBERMAN, 2001, p. 105). Estas palavras de Zilberman serviriam também para questionar a existência das bibliotecas sem livros, a leitura dissociada do livro e a influência da tecnologia nos processos de ler, de transmitir e de acumular saberes.

Ao enfrentarmos a difícil história do livro, compreendemos que conceituar esse objeto apenas por sua forma ou por seu conteúdo não nos ajudaria a estabelecer as importantes relações que ele trava com a sociedade, a influência que exerce para o regime de liberdade de idéias e para a formação política e econômica do ocidente. Mas, certamente, não podemos nos furtar ao 
diálogo necessário entre a linguagem, a escrita e os meios de comunicação do pensamento. Segundo Spirkin (1972), a escrita constituiu a forma visual de fixar a linguagem, surgindo quando a sociedade já havia alcançado um nível elevado de desenvolvimento. Portanto, um produto normal da ampliação dos meios de intercomunicação das pessoas, que são estimuladas pelas necessidades práticas da vida social. A escrita é o resultado da atividade criadora e consciente dos seres humanos. Como linguagem articulada, adquire um caráter até certo ponto independente e constitui uma forma de atividade extremamente abstrata.

A escritura pictográfica evoluiu gradativamente no sentido da significação. Da representação completa do objeto, o homem passou à representação esquemática. Por sua vez, a escrita ideográfica ou hieroglífica constituiu um sistema de signos e regras acerca de seu emprego que serviu para comunicar um pensamento qualquer. Do ponto de vista do desenvolvimento do pensamento, o aparecimento do alfabeto significou que o homem chegou a ter a idéia de que a palavra consta de elementos particulares. O sistema alfabético, portanto, surgiu no estágio em que a linguagem fonética e o pensamento abstrato haviam alcançado seu pleno desenvolvimento. A escrita fonética, através da linguagem, se converteu em realidade material do pensamento. Então, ao proporcionar ao pensamento um caráter de certo modo independente (da realidade física dos objetos), a linguagem foi uma das forças que contribuíram para criar não somente uma cultura espiritual, como para desenvolver a cultura material.

O pensamento humano, que opera com conteúdos dependentes da palavra, implica sempre uma influência recíproca entre o sujeito pensante e o conteúdo que a palavra encerra e a linguagem é vista como o instrumento do pensar, sua realidade imediata, tanto para o ouvinte quanto para o falante. Merleau Ponty (1992, p. 22) amplia esse conceito e afirma que "a palavra não é a tradução de um sentido mudo, mas criação de sentido. A linguagem não 'veste' idéias: ela encarna significações, estabelece a mediação entre o eu e o outro e sedimenta os significados" que constituem a cultura.

O pensamento, ainda em Spirkin, nasce junto com a linguagem e constitui a atividade cognoscitiva do sujeito feita imediatamente por meio da palavra. A linguagem cumpre, então, dois papéis: um como fator de comunicação (objeto - relação do sujeito com o objeto - relação existente entre sujeitos), outro como organizador do pensamento. Gorsky (1966, p. 68-105) confirma o discurso de Spirkin, dizendo que a linguagem está vinculada ao pensamento direta e indissoluvelmente e é essa conexão essencial que determina o papel que a linguagem desempenha na esfera do conhecimento. Richaudeau (1972) adiciona ênfase à tese, 
considerando que a riqueza do aparelho lingüístico permitiu a transcendência da sua função inicial e a linguagem se transformou em suporte do conhecimento, da imaginação, do sonho, dos prazeres. A linguagem não exprime somente o pensamento humano pré-existente, mas se constitui no próprio pensamento. ${ }^{1}$

Ainda em Gorsky, a linguagem não só constitui uma condição necessária para a formação de nossos pensamentos, como também permite consolidar os êxitos da atividade cognoscitiva do indivíduo, fixar a experiência adquirida por uma geração e transmitida às gerações futuras. Portanto, o papel da linguagem para o conhecimento se revela a partir da transmissão dos conhecimentos adquiridos, na passagem do nível sensorial para o racional e no processo de formação de conceitos, tanto do discurso da ontogênese, como da filogênese.

Martins (1957, p. 25) afirma que são problemas até agora não resolvidos o momento e o processo em que a linguagem se diversificou em idiomas, e a linguagem auditiva se diversificou em linguagem visual, com a invenção dos primeiros sistemas de escrita. A escrita seria apenas um sistema de linguagem visual mais perfeito ou menos obscuro dentre inúmeros outros como: os desenhos, a mímica, os códigos de sinais marinhos e terrestres, luminosos ou não, os gestos.

Usando a cronologia organizada por Zilberman (2001p. 121-123), temos que:

\begin{tabular}{|c|c|}
\hline 2300 a.C. & Os egípcios usam o papiro para fixar matéria escrita. \\
\hline 750 a.C. & $\begin{array}{l}\text { Invenção do alfabeto grego, adaptado da escrita fenícia e acrescido de signos que } \\
\text { representam vogais. }\end{array}$ \\
\hline Séc.V. a.C. & $\begin{array}{l}\text { Apogeu da cultura ateniense, com o desenvolvimento da tragédia, da comédia e da filosofia. } \\
\text { Comercialização de obras escritas por meio de livreiros. }\end{array}$ \\
\hline Séc. IV a.C. & Escolarização da juventude e expansão da aprendizagem da leitura escrita. \\
\hline 310 a.C. & $\begin{array}{l}\text { Fundação em Alexandria, por Ptolomeu I, de uma biblioteca para acolher e estudar a } \\
\text { produção escrita da Antiguidade }\end{array}$ \\
\hline Séc. II a.C. & $\begin{array}{l}\text { Ascensão de Pérgamo como centro cultural; desenvolvimento do pergaminho para a fixação } \\
\text { material do escrito. }\end{array}$ \\
\hline 105 a.C. & Invenção do papel na China, creditada a Tse'ai Lun. \\
\hline Séc. I a.C. & $\begin{array}{l}\text { Expansão da leitura silenciosa em Roma, onde se encontravam livrarias administradas por } \\
\text { libertos }\end{array}$ \\
\hline Sécs. II e III d.C. & $\begin{array}{l}\text { Expansão do uso do códice, em lugar do rolo; o pergaminho torna-se o material preferido } \\
\text { para fixação de textos escritos, substituindo o papiro. }\end{array}$ \\
\hline 793 & Introdução do uso do papel no mundo árabe. \\
\hline Séc. XII & $\begin{array}{l}\text { Consolidação da escrita em palavras separadas. Predomínio da leitura silenciosa sobre a } \\
\text { leitura oral. }\end{array}$ \\
\hline 1270 & Construção, na Itália, do primeiro moinho de fabricação de Papel. \\
\hline Sécs. XIII e XIV & $\begin{array}{l}\text { Aparecimento das primeiras universidades européias. Desenvolvimento do comércio de } \\
\text { obras escritas, produzidas manualmente por copistas. }\end{array}$ \\
\hline 1450 & Produção de papel na Europa. Apresentação, por Gutenberg, do primeiro exemplar impresso \\
\hline
\end{tabular}

\footnotetext{
${ }^{1}$ Alguns linguistas e psicólogos contestam essa tese, principalmente os discípulos de Piaget, que deduziram de seus trabalhos experimentais a pré-existência do pensamento sobre a linguagem. Cf. Richaudeau, 1972, p. 208. No entanto, vale a pena investigar se os experimentos piagetianos são da ordem da ontogênese apenas, ou se estendem também à filogênese.

Enc. Bibli: R. Eletr. Bibliotecon. Ci. Inf., ISSN 1518-2924, Florianópolis n. esp., 1. sem. 2009.
} 


\begin{tabular}{|l|l|}
\hline & da Bíblia, inaugurando a era do livro manufaturado industrialmente. \\
\hline 1476 & Fundação por William Caxton, da primeira tipografia na Inglaterra. \\
\hline Séc. XVI & $\begin{array}{l}\text { Expansão da indústria tipográfica por toda a Europa. Até 1550, fixação da forma do livro, } \\
\text { incluindo capa, título, nome do autor e demais características gráficas. }\end{array}$ \\
\hline 1564 & $\begin{array}{l}\text { Publicação em Roma, do Index Librorium Prohibitorum, pelo Papa Pio IV, estabelecendo a } \\
\text { censura religiosa. }\end{array}$ \\
\hline 1605 & $\begin{array}{l}\text { Publicação de O Engenhoso fidalgo Dom Quixote de la Mancha, de Miguel de Cervantes, } \\
\text { tematizando a febre da leitura na Europa moderna, onde então funcionam mais de 250 } \\
\text { tipografias. }\end{array}$ \\
\hline Séc. XVIII & $\begin{array}{l}\text { Expansão da alfabetização e da imprensa entre a população. Crescimento do público leitor, } \\
\text { sobretudo entre a classe burguesa ascendente. Expansão do romance. }\end{array}$ \\
\hline Início séc. XIX & $\begin{array}{l}\text { Barateamento do custo da produção do livro e dos jornais, graças à industrialização do } \\
\text { papel. Expansão da imprensa e do romance folhetim. Consolidação do público feminino. }\end{array}$ \\
\hline 1857 & $\begin{array}{l}\text { Publicação de Madame Bovary, de Gustave Flaubert, cuja protagonista é iludida pelos } \\
\text { enredos folhetinescos das novelas lidas na adolescência. }\end{array}$ \\
\hline Sécs XIX e XX & $\begin{array}{l}\text { Escolarização obrigatória da população infantil. Expansão da literatura de massa. Pesquisas } \\
\text { no âmbito da Sociologia da Leitura. Propostas teóricas e aplicadas de alfabetização popular. } \\
\text { Difusão das teorias sobre o efeito da leitura e a emancipação do leitor. }\end{array}$ \\
\hline $\begin{array}{l}\text { Final séc. XX e início } \\
\text { do XXI }\end{array}$ & $\begin{array}{l}\text { Expansão da tecnologia digital e das redes de comunicação virtual via computador. } \\
\text { Aparecimento de multimídias, CD-ROM, E-Books. Discussões sobre o futuro do livro, da } \\
\text { leitura e da literatura. }\end{array}$ \\
\hline
\end{tabular}

Um rápido olhar nessa linha do tempo da evolução dos modos e meios de transmissão do saber pode nos dar uma explicação sobre a angústia em que vivemos na era atual que ameaça extinguir um objeto, com o qual travamos relação afetiva por quinhentos anos. O que significa também afirmar que acumulamos esses objetos quer fossem eles produzidos com a estética com a qual costumamos nomear "livro", quer com as estéticas anteriores e posteriores que mudavam em função das tecnologias de produção do objeto.

Quer nos parecer que o foco da questão é a possibilidade de perda de memória auxiliar acumulada, proporcionada por fatores de preservação do objeto. Os livros são objetos que se conservaram muito bem ao longo do tempo e as bibliotecas demonstram isto em suas seções de obras raras. Eles foram guardados, mantendo a integridade do saber ali registrado, estabelecendo a maior rede de pensamento que a sociedade jamais experimentou.

Na obra de Ray Bradbury, Fahrenheit 451, o tema do fim do livro é sugerido na trama futurista em que um grupo de pessoas resistentes ao sistema de controle social imposto pelo regime das mídias televisivas que queimava livros, resolve criar uma sociedade secreta em defesa da literatura, onde cada pessoa se compromete a decorar uma ou mais obras da literatura e se responsabilizar por sua transmissão oral. Os livros eram lidos, decorados e imediatamente queimados à temperatura de 451 graus fahrenheit. 
Quero que conheça Jonathan Swift, autor daquele pernicioso livro político, As viagens de Gulliver! E esse sujeito aqui é Charles Darvin, e esse aqui é Schopenhauer, esse outro é Einstein, e este aqui ao meu lado é o Senhor Albert Schweitzer, um filósofo realmente muito gentil.[...] E também somos queimadores de livros. Lemos e os queimamos, por medo que sejam encontrados.[...] Tudo o que queremos fazer é manter o conhecimento que, pensamos, precisamos manter intacto e seguro. [...] Passaremos os livros adiante a nossos filhos, de boca em boca, e deixaremos que nossos filhos, por sua vez, sirvam a outras pessoas. É claro que muito se perderá dessa maneira.(BRADBURY, 2003, p.186-188)

Fahrenheit 451 estabelece uma nova relação da memória com a oralidade, quando verifica que a sociedade da escrita está ameaçada de desaparecer. A rede de pensamento organizada pelos livros seria humanizada, protegida pela disseminação oral do conhecimento. Embora os "homens-livros" se preocupassem com a integridade da obra e do autor, sabiam também que o processo de transmissão oral não garantiria essa integridade. Somente a acumulação de itens individuais preservados em sua originalidade pode nos dar essa garantia. A memória individual e, ao mesmo tempo, coletiva é representada na obra de Bradbury pelos heterônimos que habitam cada um dos personagens. Por essa obra de ficção podemos entender que a leitura sobrevive ao livro e, como assinala Zilberman, na época atual "a leitura e a escrita antecedem e sucedem os meios utilizados para sua gravação num dado tipo de material, de modo que a troca desse por outro - disco rígido, $\mathrm{CD}$ ou site na internet - representam tão somente um outro passo (ou vários) na direção do progresso e do aperfeiçoamento tecnológico.” (ZILBERMAN, 2001, p. 106).

O e-book, ou livro eletrônico, já disputa o mercado editorial mundial. Na feira de Frankfurt deste ano mais de $30 \%$ dos itens expostos eram digitais ${ }^{2}$. As editoras investem somas incalculáveis para ampliar o universo de livros digitais e aperfeiçoar os aparelhos de leitura (leitores). Copiando o aspecto do livro tradicional em formato e tecnologia de leitura - até as páginas podem ser "folheadas", o e-book carrega em seu conceito dois atributos: é um dispositivo para leitura e uma biblioteca digital, pois a capacidade de armazenamento de textos digitalizados pode chegar, até este momento, a cerca de duzentos livros digitais.

Parece-nos então que o livro em sua forma tradicional possa deixar de ser produzido, tendo em vista os benefícios que a tecnologia digital nos apresenta em relação à velocidade de acesso aos textos, à compressão de armazenamento de dados e, com os novos leitores digitais em formato de bolso, à portabilidade. Não há ainda indícios, a partir dessas novas tecnologias, de que se extinguirão a leitura e as bibliotecas. 


\section{A LEITURA}

Meu primeiro livro era de pano, e foi-me presenteado por meu pai quando eu fiz dois anos. Portanto, comecei a ler um livro com essa idade, embora aos dois anos fosse incapaz de compreender a escrita e de reproduzi-la com minha mão. "Tic-tac vai à escola com seus livros na sacola" foi inteiramente decorado por repetição oral e fixação das imagens. Ler, portanto, independe do livro e da escrita. $\mathrm{O}$ ato de ler é visual e nisto permanecemos atuais face à cultura contemporânea. Lemos um texto, um quadro, uma fotografia, um filme. Lemos o mundo.

$\mathrm{Na}$ antiguidade, a passagem da leitura oral, compartilhada, para a leitura individual, silenciosa, inaugura uma nova experiência humana de criação de mundos íntimos. Da leitura pública, a partir do método escolástico (lectio - sensus - exegese) à leitura de mundo, confere-se ao ato de ler a liberdade de criação. Como comenta Manguel, “[...] os produtos dessas escolas, os novos humanistas, abandonaram a sala de aula e o fórum público e, como Rhenanus, retiram-se para o espaço fechado do gabinete ou da biblioteca, para ler e pensar isolados.”(MANGUEL, 1997, p. 42).

A leitura começa com os olhos. Manguel se pergunta por meio de qual alquimia as letras se tornam palavras inteligíveis; o que acontece dentro de nós quando nos defrontamos com um texto; de que forma as coisas, substâncias - sejam elas cores, formas dos objetos -, tornam-se legíveis; finalmente, o que significa ler. Essa é a questão que percorre toda a sua obra Uma história da leitura da qual nos valemos neste momento para dialogar, sabendo que não estamos dialogando com apenas um autor, mas com uma rede de fontes intelectuais que expressam a memória - mundo de Alberto Manguel.

Paulo Freire (2005) discute a leitura do mundo em palestra sobre a importância do ato de ler e as relações da biblioteca popular com a alfabetização de adultos, e no artigo em que expõe a experiência de alfabetização de adultos desenvolvida por ele e sua equipe nas ilhas da costa africana São Tomé e Príncipe. Diz Freire que a leitura de mundo precede a leitura da palavra, que linguagem e realidade se prendem mutuamente. $\mathrm{O}$ autor apresenta a tese de que o ato de ler se funde, em certo sentido, com a memória.

\footnotetext{
${ }^{2}$ Páginas virtuais: editores se acotovelam em Frankfurt para entender como as novas tecnologias podem revolucionar a leitura. O Globo, sábado, 18 de out. 2008. (Prosa \& Verso)
} 
Ao ir escrevendo este texto, ia "tomando distância" dos diferentes momentos em que o ato de ler se veio dando na minha experiência existencial. Primeiro, a leitura do mundo, do pequeno mundo em que me movia; depois, a leitura da palavra que nem sempre, ao longo de minha escolarização, foi a leitura da "palavramundo". A retomada da infância distante, buscando a compreensão do meu ato de ler o mundo particular em que me movia - e até onde não sou traído pela memória-, me é absolutamente significativa. Nesse esforço a que me vou entregando, re-crio, e re-vivo, no texto que escrevo, a experiência vivida no momento em que ainda não lia a palavra. Me vejo então na casa mediana em que nasci, no Recife [...] (FREIRE, 2005, p. 12).

A importância do contexto como antecedente ao texto da leitura é fundamental para a teoria de alfabetização de Paulo Freire. O contexto, ou mundo imediato, é representado pela experiência vivida do leitor, como aquela indicada pelo autor na citação acima. Mais adiante em sua fala, Freire explicita sua tese ao afirmar que "a leitura da palavra não é apenas precedida da leitura de mundo, mas por uma certa forma de "escrevê-lo" ou de "reescrevê-lo", quer dizer, de transformá-lo através de nossa prática consciente” (FREIRE, 2005, p. 20). A leitura de mundo do alfabetizando deveria sempre prevalecer à leitura de mundo do alfabetizador, pois só assim o processo de conhecimento poderia ocorrer, no sentido transformador.

A leitura é, assim, o processo que nos permite interagir com o mundo, armazenar lembranças, produzir novos conhecimentos. Nesse sentido, o ato de ler é vital e não se prende apenas a um dispositivo de leitura, como, por exemplo, o livro. A leitura alimenta a imaginação e o começo desse processo se inicia com a vida e se encerra com a morte. Do mesmo modo que a linguagem, leitura e memória fixam a experiência adquirida por uma geração para ser transmitida às gerações futuras.

Não foi apenas Paulo Freire que pensou a leitura como leitura-mundo ou memória-mundo. Kafka, citado por Manguel (1997, p. 111) ao comparar o livro com o mundo, ou a obsessão das pessoas pela posse do livro diz que: "Um livro não pode tomar o lugar do mundo. [...] Um homem não pode dominar sua própria experiência por meio de outra personalidade.[...] Tentamos aprisionar a vida num livro, como um pássaro canoro na gaiola, mas não funciona." Sócrates também afirmava que somente o que o leitor já conhece pode ganhar vida com uma leitura, indicando, desta forma, que a experiência pessoal seria a base para a produção do conhecimento. A idéia de rede de informações ou de conhecimento está já delineada nessas discussões sobre o processo de criação, assim como a possibilidade de haver tantas leituras possíveis quanto fossem os leitores. É, portanto, no indivíduo que se dá o ato complexo de ler, muitas vezes igualado à dinâmica da memória. 
Ainda na História da leitura, Manguel comenta que o poeta americano Walt Whitman dizia que nossa tarefa é ler o mundo, pois esse livro colossal é a única fonte de conhecimento para os mortais.

\begin{abstract}
Dizer que lemos - o mundo, um livro, o corpo - não basta. A metáfora da leitura solicita por sua vez outra metáfora, exige ser explicada em imagens que estão fora da biblioteca do leitor e, contudo, dentro do corpo dele, de tal forma que a função de ler é associada a outras funções corporais essenciais. Ler - como vimos - serve como um veículo metafórico, mas para ser compreendido precisa ele mesmo ser reconhecido por meio de metáforas. (1997, p. 198).
\end{abstract}

Manguel, comentando o que Santo Agostinho argumenta sobre os modos de ler, sugere que não devemos usar o livro apenas como apoio para o pensamento, nem confiando nele como se confiaria na autoridade de um sábio; mas tomando dele uma idéia, uma frase, uma imagem, ligando-a a outra selecionada de um texto distante preservado na memória, amarrando o conjunto com reflexões próprias e produzindo, na verdade, um texto novo de autoria do leitor. Mangel, no ensaio O computador de Santo Agostinho (MANGUEL, 2000, p. 273-291) nos conta que Santo Agostinho sabia que todo leitor cria, ao ler, um espaço imaginário, feito da pessoa que lê e do reino das palavras lidas. Diz ainda o autor que "cada leitura prolonga outra, iniciada em alguma tarde de milhares de anos atrás e da qual não sabemos nada; cada leitura projeta sua sombra na página seguinte, emprestando-lhe conteúdo e contexto." Não há conclusão para a leitura. A leitura é um processo sempre incompleto, não linear, mesmo que circunstancialmente a leitura da escrita nos force a uma determinada direção, da esquerda para a direita, como na cultura ocidental.

\title{
4 COMO LER O MUNDO ATUAL?
}

Se a leitura é parte integrante do processo de conhecimento, independe do objeto a ser lido, e se é também inconclusa, como pensar a leitura, o leitor e o mundo a ser lido nessa era ubíqua, em que os objetos se fundem em escrituras digitais, em que o pensamento se constrói por redes de narrativas que nascem concomitantemente à produção dos objetos virtuais?

Vimos anteriormente que os livros não desapareceram, apenas mudam seu formato, assim como no passado transformaram-se de rolos a códices. Muito menos as bibliotecas deixaram 
de existir. Cada vez mais se digitalizam obras para comporem as bibliotecas digitais e as bibliotecas dessas bibliotecas, às vezes com outras nomeações como, por exemplo, os repositórios digitais.

O exemplo do uso de uma nova tecnologia para a transformação da sociedade é dado por Martinho Lutero, monge responsável pelo movimento da Reforma, que em 1521 utiliza as facilidades tecnológicas da impressão e publica a Bíblia em língua vernácula, o alemão, possibilitando assim que se desse início, no ocidente, ao movimento de alfabetização. A revolução causada na Igreja romana, com o aparecimento do protestantismo, permitiu que a leitura da escrita, antes apenas em latim, absorvesse outras camadas da população, como crianças e mulheres. Segundo Manguel (1997, p. 89), “a criança, aprendendo a ler, é admitida na memória comunal por meio de livros, familiarizando-se assim com um passado comum que ela renova, em maior ou menor grau, a cada leitura."

Passados cinco séculos, a escrita digital que ocorre no mundo virtualizado da rede mundial de computadores pode ser compreendida por dois objetos: os blogs e os websites. De acordo com Lopes (2003), Blog é uma abreviatura de web log e significa uma página na web que se propõe a ser um diário pessoal com acesso público. Os blogs são, assim, publicações freqüentes, organizadas cronologicamente, de considerações pessoais e links para a web. Diferem dos websites por sua estrutura conversacional. Enquanto nos blogs as matérias são "postadas" (posts) por data e esses posts constituem toda a sua essência, os websites harmonizam uma rede de informações fixas, sobre um tema específico, que pode ter como autoria uma pessoa física ou uma pessoa jurídica.

Tanto blogs, quanto websites são os depositários das narrativas da atualidade. Artigos acadêmicos, crônicas, fotografias, filmes, críticas literárias, artísticas, científicas, todas essas formas de divulgação da informação são publicadas nessas mídias. A interatividade dos blogs se faz pelas postagens tanto do autor quanto do leitor, aliada às salas de "bate-papo" que, normalmente, ficam em linha durante todo o tempo em que o internauta está "plugado". A informação circula em rede ou vias de comunicação, sempre transformando outras e a si mesma, num processo de criação contínua, como ocorre com nossa memória individual.

A descontinuidade da leitura nessas mídias informáticas não difere - a não ser pela velocidade - das formas de leitura do livro, quer seja em seu formato tradicional, quer seja no formato hipertextual. O hipertexto é um modo de pensar essencialmente em rede e por associação o que as notas de texto e as referências incluídas no livro em papel já proporcionavam ao leitor. A falta de linearidade característica da construção da escrita hipertextual impede a sua Enc. Bibli: R. Eletr. Bibliotecon. Ci. Inf., ISSN 1518-2924, Florianópolis n. esp., 1. sem. 2009. 
completude e a sua conclusão; mas sobre isto vimos, anteriormente, que essa é uma operação inerente à leitura e não à hiprtextualidade.

O que a tecnologia da informação e da comunicação nos apresenta hoje são problemas de outra natureza; são questões mais ligadas à memória de mundo do que à leitura de mundo. Esses problemas dizem respeito à preservação da informação que, naturalmente, muda com uma nova tecnologia. Não é a leitura que nos preocupa. Enquanto seres humanos continuaremos a ler o mundo do nosso presente, mesmo que para tal seja necessário estar "plugado" à máquina. O que aterroriza a sociedade contemporânea é abdicar de suas memórias auxiliares, de seus tesouros materiais.

A "sociedade do menos" começa a se impor: menos poluição, menos desperdício de alimentação, menos consumo de água. E por que não, menos memórias auxiliares, arquivos, bibliotecas, menos museus? A memória pode ser construída e reconstruída, reciclando-se continuamente. Ainda há espaço para muitas tecnologias da informação. O mundo ainda é muito desigual em "letramento", ou níveis de leitura. Muitas crianças nunca tiveram o prazer de ler um livro, nem em papel nem em formato digital. Mas é possível que venham a conhecê-lo apenas na tela de seus celulares, ou na oralidade das histórias contadas.

A leitura, assim como a memória, é inerente à humanidade. Não se pode dizer o mesmo da acumulação patrimonial que inicia sua corrida nos finais do século XIX, mas parece já desacelerar neste início do XXI. Imposta por uma tecnologia digital, a preservação dos saberes se dá mais por disseminação do que por proteção. Assim como o poema de Leminski, o bicho alfabeto passa, fica o que não se escreve.

\section{REFERÊNCIAS}

BRADBURY, R. Fahrenheit 451: a temperatura na qual o papel do livro pega fogo e queima... São Paulo Globo, 2003.

CHARTIER, R. A aventura do livro: do leitor ao navegador. São Paulo: UNESP, 1998.

FREIRE, P. A importância do ato de ler em três artigos que se completam. São Paulo: Cortez, 2005. 
GORSKY, D. P. Lengaje y conocimiento. In: . Pensamiento y lengaje. Mexico:

Crijalbo, 1966. p. 68-105.

HUYSSEN, A. Seduzidos pela memória. Rio de Janeiro: Aeroplano, 2000.

LEMINSKI, P. O bicho alfabeto. Poesia Sempre: China, Rio de Janeiro: Fundação Biblioteca Nacional, v. 27, n. 14, 2007.

LOPES, A. C. K. Da possibilidade de exercício de memória criativa: internet, blogs e bloggers. 2003. Dissertação (Mestrado PPGMS) - UNIRIO, Rio de Janeiro, 2003.

MANGUEL, A. A biblioteca à noite. São Paulo: Companhia das Letras, 2006.

. No bosque do espelho: ensaios sobre as palavras e o mundo. São Paulo: Companhia das Letras, 2000.

O computador de Santo Agostinho. In: No bosque do espelho: ensaios sobre as palavras e o mundo. São Paulo: Companhia da Letras, 2000. p. 273-291.

Uma história da leitura. São Paulo: Companhia das Letras, 1997.

MARTINS, W. A palavra escrita. São Paulo: Amhenbi, 1957.

PONTY, M. M. O visível e o invisível. São Paulo : Perspectiva, 1992.

O lugar do livro hoje. Tempo Brasileiro. Rio de Janeiro, n. 142, jul-set., 2000.

PÁGINAS VIRTUAIS: editores se acotovelam em Frankfurt para entender como as novas tecnologias podem revolucionar a leitura. O Globo, Rio de Janeiro, 18 de out. 2008. (Prosa \& Verso).

RICHAUDEAU, F. Langage et action. In: . Les théories de l'action. Paris: Hachette, 1972.

SPIRKIN, A.G. Origen del lengaje y su papel en la formacion del pensamiento. In: Les théories de l'action. Paris: Hachette, 1972. 
ZILBERMAN, R. Fim do livro, fim dos leitores? São Paulo: SENAC, 2001.

\begin{abstract}
Memory is built with the present time as a starting point, through the tension between two actions: remembering and forgetting, and engages in a permanent dialogue with the objects we choose in order to analyze the condition of knowledge at a given point in time. This paper is divided into three parts. In the first part, we deal with the object "book", its appearance in society, its importance for the transmission of knowledge, its power to control people's attitudes, such as the memory-men created by Bradbury in Fahrenheit 451, and its possible decline in view of information medium technologies. The second part dissociates the act of reading from its most traditional support and deals with "reading" as an independent object, with the suggestion, based on Regina Zilberman's, Alberto Manguel's and Paulo Freire's proposals, that we are meant to read the world, irrespective of the mechanisms used in order to achieve this ultimate aim. In the third and last part, we present some signs of possible ways in which memory may exist in the cyber world, with comments on the role of blogs and websites in relation to the written word on paper.
\end{abstract}

Keywords: Virtual memory. Book. Reading. Blogs. Digital heritage. 
Originais recebidos em: 05 de março de 2009

Aceitos para publicação em: 14 de maio de 2009

Enc. Bibli: R. Eletr. Bibliotecon. Ci. Inf., ISSN 1518-2924, Florianópolis n. esp., 1. sem. 2009. 